\title{
Control de la tierra en la cabecera del Valle de Lluta*
}

\author{
Milka Castro \\ Miguel Bahamondes
}

\section{INTRODUCCIÓN}

El presente artículo contiene algunos resultados de estudios que los autores iniciaran en 1979 en la zona altiplánica, comprendida entre los $17^{\circ} 37^{\prime}$ y $18^{\circ} 30^{\prime} \mathrm{LS}$, Provincia de Parinacota, donde las condiciones climáticas imperantes han impuesto fuertes restricciones a las actividades productivas de la población local de aymará hablantes. Su economía descansa en la explotación del recurso que mejor se ha adaptado a las peculiaridades ecológicas. el ganado camélido y ovino. Conocer los mecanismos desarrollados por la población para proveerse de los bienes que necesita y no produce fue uno de los principales objetivos de la investigación. Los resultados mostraron una compleja red de relaciones de intercambio de productos que se extendía desde pueblos y ferias en países limítrofes (Perú y Bolivia) hasta los valles precordilleranos y costeros de Chile y Perú (Figura 1).

La relevancia de los intercambios con los asentamientos ubicados en la cuenca del río Lluta, especialmente los de la precordillera, trasladó el estudio al poblado de Socoroma (3.400 mts. snm.). En esta localidad se ha trabajado en las relaciones de producción vigentes para controlar recursos dentro y fuera de la comunidad. Las modalidades empleadas para el control de la tierra por una población que, en un porcentaje importante, ha trasladado su residencia permanente a la ciudad de Arica constituyó uno de los objetivos de investigación en este pueblo (CAstro, M. y M. Bahamondes, 1987). En relación a los vínculos entre diferentes ecosistemas altitudinales en el contexto de la "verticalidad" es posible sostener, a partir de la evaluación que hace la población local, que las relaciones de intercam-

* Investigación patrocinada por el Departamento Técnico de Investigaciones de la Universidad de Chile y UNESCO - MAB/6. 


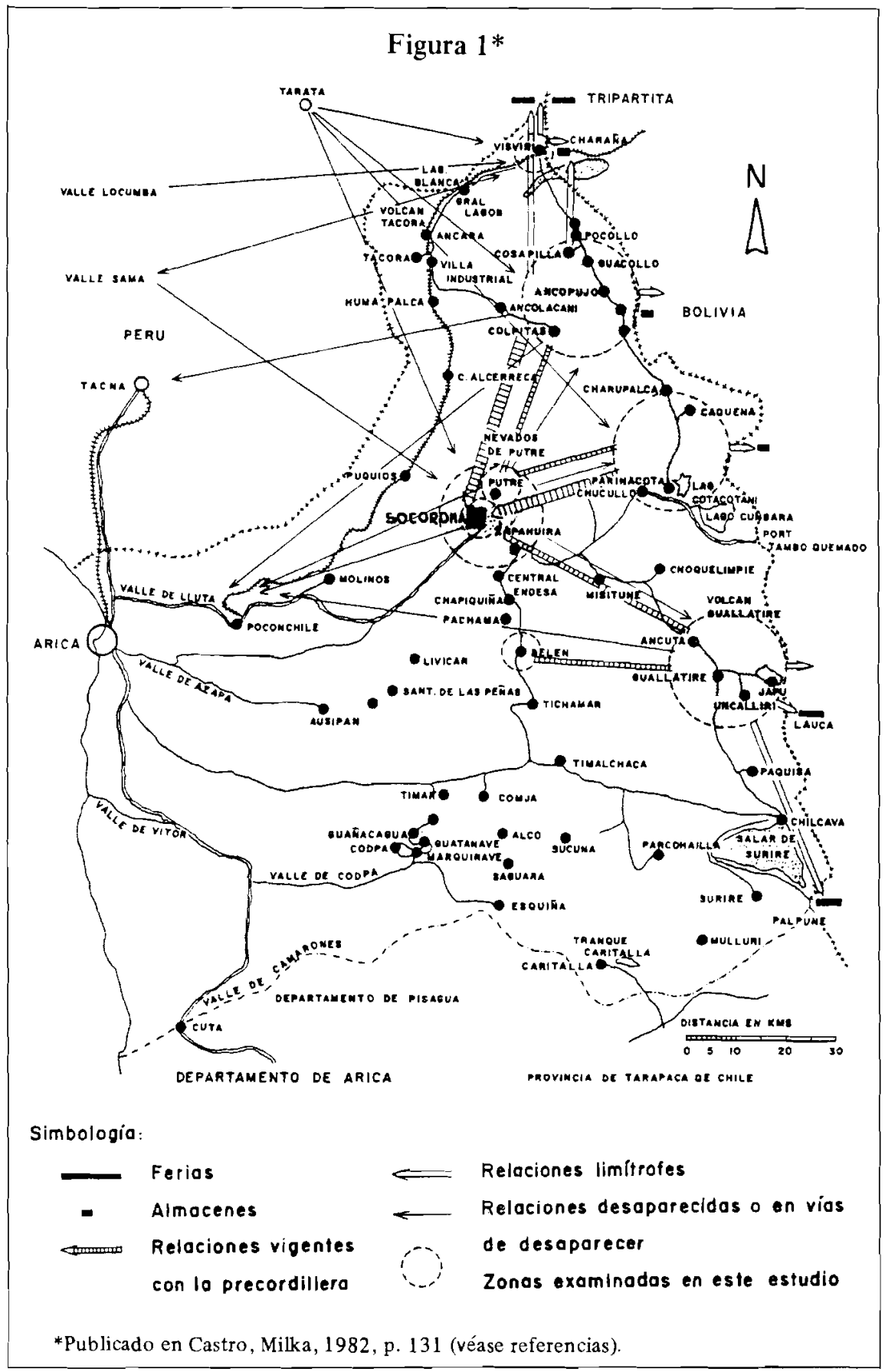


bio de productos y alianzas matrimoniales tienden a disminuir notoriamente entre altiplano y precordillera. Algo similar acontece entre Socoroma y la cabecera del valle de Lluta; acá, además de las relaciones anteriores, se ejercía un control directo sobre los terrenos situados entre la quebrada de Socoroma y la localidad de Molinos, donde se encuentra el caserío del mismo nombre a una distancia aproximada de $55 \mathrm{~km}$ de la ciudad de Arica.

\section{Metonología}

Las tierras agrícolas localizadas en la parte superior del sistema hidrográfico del río Lluta, están bajo el control de las familias que residen en los poblados más cercanos de la precordillera. El espacio productivo se encuentra interrumpido entre Socoroma y las proximidades de Vilacollo, debido a la estrechez del valle y fuertes pendientes. En consecuencia, se han identificado claramente dos sectores: 1) la cabecera de] valle, y 2) los pueblos de la precordillera. Ambos sectores, como se ha señalado, están unidos por el control que ejerce la población del segundo sector sobre el primero.

Las relaciones descritas se comprobaron en el trabajo de campo realizado en Socoroma. Frecuentemente se hacía mención a las tierras que tienen las familias de este pueblo, de Putre y otros, en el sector de Molinos "hacia arriba". En opinión de los socoromeños las tierras de Molinos "hacia a bajo" no pertenecen a aquellos poblados.

Con la finalidad de caracterizar la forma y magnitud que asume este control de tierras en la cabecera del valle de Lluta, se analizó la informacić 1 de propiedad predial registrada en 1960, en el sector comprendido entre Tocontase y Arancha (Figura 2), comparándola con datos dctualizados en el sector e información obtenida en Socoroma entre los años 1983 y 1988.

\section{PARENTESCO, COMPLEMENTARIEDAD Y CONFLICTO}

A pesar de las grandes distancias que separan los pueblos andinos entre sí, es difícil establecer límites más allá de su perímetro poblado; los factores de la producción se articulan mediante complejas redes de relaciones. En el caso de Socoroma ha sido frecuente encontrar familias que poseen tierras en zonas aledañas y de similar altitud, como ocurre con Putre, Zapahuira y Murmuntani, y en zonas más bajas como Lluta. En ambas situaciones la herencia, que descansa en las relaciones de parentesco; la compra; la cesión ("préstamo") y la mediería han sido las formas más frecuentes empleadas para acceder a la tierra. Sin embargo, este proceso no ha estado exento de conflictos; al iniciarse la inscripción legal de los predios quedó en evidencia una fuerte disputa por el control de la tierra que se manifestó en la usurpación y pleitos por la propiedad legal. 


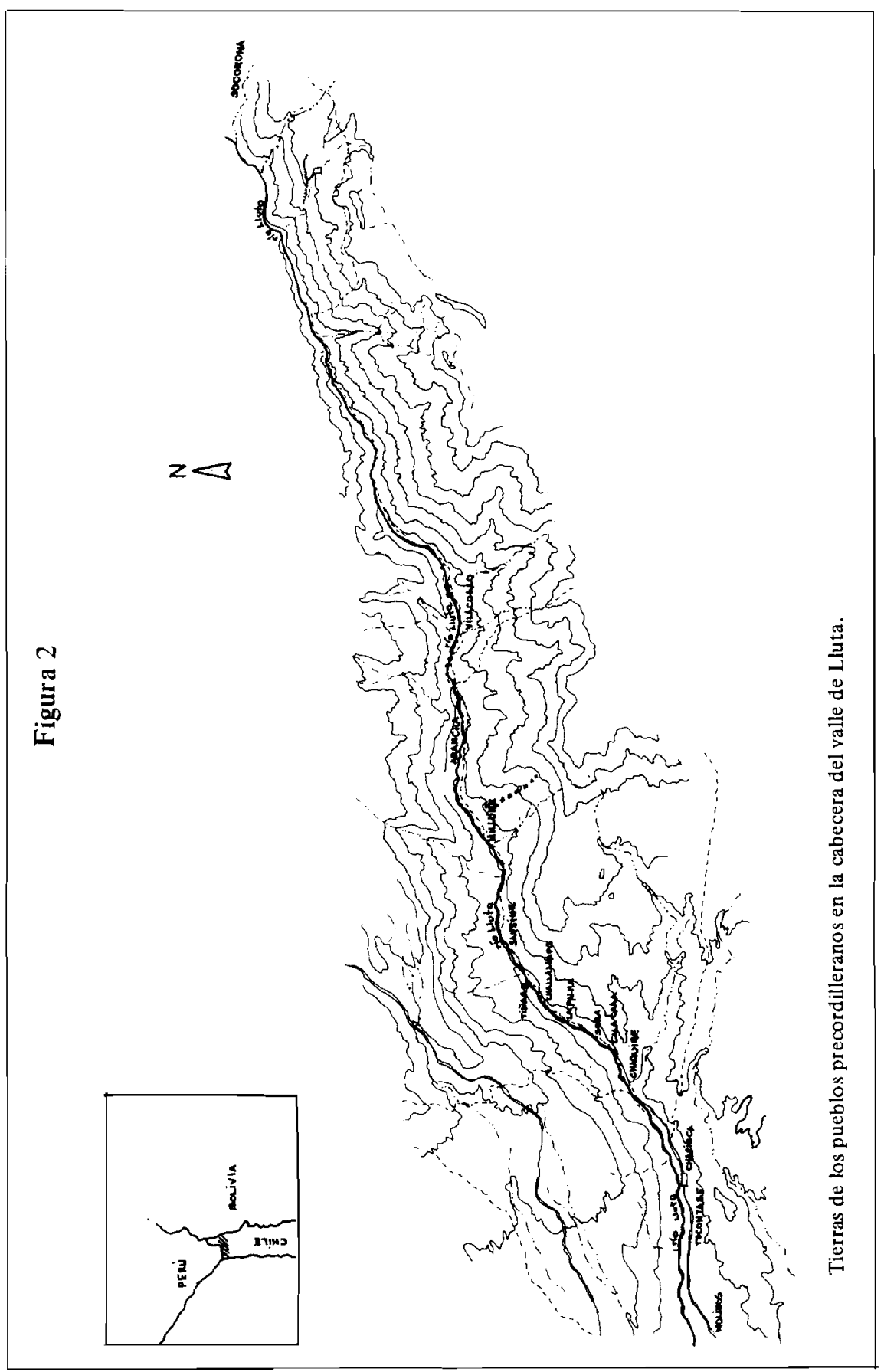


En el caso específico de la cabecera del valle estudiado, la apropiación de tierras ha sido hecha por las personas que se encontraban cultivando terrenos de propietarios ausentes. Los pleitos entre hermanos es otra de las formas en que se manifiesta el conflicto por la propiedad de la tierra. Estos problemas adquieren mayor complejidad a raíz de las modalidades consuetudinarias empleadas por la población andina, para transferir la propiedad, como lo expresa un campesino: "...la gente compraba así, en palabra no más... de repente: te vendo estos terrenitos... así no más compraban...", y agrega... "acá hay mucha gente que se posesionó de terrenos a la mala". Estas opiniones se escuchan frecuentemente, también en los valles de la precordillera y en el altiplano.

La importancia otorgada por diversos autores a las relaciones de complementariedad y/o reciprocidad en el área andina, ha influido, de alguna manera, en la menor atención que se ha prestado a los conflictos que surgen por el control de la tierra. Conflictos que trascienden el parentesco, la solidaridad y vecindad.

Como veremos más adelante, las personas o familias que cultivaban en la cabecera del valle, residían preferentemente en la precordillera. Los testimonios al respecto abundan: "...se iba a sembrar a Lluta..."; "...algunos de acá cultivan, hay familiares..."; "...se van a cultivar de Socoroma...".

Por otra parte, asumiendo que actividades productivas y religiosas conforman una unidad donde las últimas contribuyen a la reproducción de las primeras, cualquier conflicto que surja en torno, por ejemplo, al control de la propiedad de la tierra, debería tener alguna manifestación en el plano ideológico.

Una de las instancias que servia de nexo entre la población de los dos sectores señalados, la constituía el ceremonial efectuado en la Iglesia de Sora, hasta que una avenida del río Lluta, junto con arrastrar gran cantidad de tierras cultivadas, la destruyó. Los socoromeños rescataron la imagen de la Virgen Candelaria y las campanas, para trasladarlas a la Iglesia de Socoroma. Hoy, cuando el control directo sobre la cabecera del valle ha disminuido, los habitantes de Sora están reconstruyendo la Iglesia y demandan de Socoroma la restitución de los bienes de aquélla; sin embargo, el fervor y el derecho que aseguran tener los residentes de este pueblo, desde tiempos de sus abuelos, sustentan una rotunda negativa.

No obstante, subyace a las formas y características de las relaciones un objetivo básico, la complementariedad de recursos o productos. La cabecera del valle ha abastecido de maíz a zonas de mayor altitud; sus actuales habitantes recuerdan que hasta hace un par de décadas llegaban caravanas de setenta a ochenta llamos procedentes de Bolivia, trayendo carne o charqui y papas para trocarlas por maíz. Lo mismo acontecía con los subproductos de camélidos de la zona de Parinacota 
y Caquena. Putreños y socoromeños llegaban en mulas y burros con papas, las que cambiaban por maíz. ${ }^{1}$.

Un ejemplo ilustrativo de los niveles alcanzados en la complementaridad entre pisos, lo encontramos en el plano de los cultivos. A fin de evitar, en opinión de los lluteños, la regresión genética de uria variedad de papas, cuya denominación vernacular es llokj'cha, se procedía a un intercambio alternado de semillas entre la cabecera del valle y los pueblos de Putre y Socoroma: "...la semilla aguanta un sembrío no más..., nosotros cómo lo hacíamos: en mayo estábamos cosechando la papa aquí y mandábamos la semilla para arriba y ellos sembraban allá y nos mandaban, devolvían otra vez...".

\section{Control de la tierra}

El estudio se efectuó teniendo como base la información obtenida, para 106 predios localizados entre Tocontase y Arancha (registrada en un mapa); 25 predios quedaron excluidos por aparecer como propiedad fiscal, eriazos, y por carecer de antecedentes de su propietario. Por tanto, se trabajó con 81 predios.

Uno de los primeros resultados que arroja el análisis, corrobora la información obtenida en Socoroma. Los propietarios oriundos de este pueblo y de Putre controlan el $67 \%$ de los predios y el $49 \%$ de la superficie del área. (Cuadro $\mathrm{N}^{\circ}$ 1.)

En el Cuadro $\mathrm{N}^{\circ} 1$ la información se ordenó considerando la procedencia de los propietarios. Si se deja a un lado aquellos sujetos procedentes de Bolivia, Perú y Sur de Chile, aparece Chapiquiña como el único poblado precordillerano que pertenece al sistema hidrográfico del río de Azapa.

En el Cuadro $N^{\circ} 2$ aparece señalada la distribución y localización de los predios y la procedencia de los propietarios.

\footnotetext{
1 Un campesino de Socoroma describió el camino hasta Lluta: “... empezando de acá, se sube allá, se llama Cementerio, una partecita donde están haciendo adobes se llama Sunaraña, porque tiene un alojamiento, dicen que los bolivianos venían con charqui, con carne y entonces en aymará se llama Sune, entonces ahí tenían que descargar, entonces decían Sunejaraña, jaraña quiere decir hay que desatarlo; después arriba donde está dando la curva para el otro lado, la huella se llama Tukurine, después ese cerrito que está parado se llama Kavanchia; después al otro lado hay un cerrito igual que gallo, se llama Gallo, después más arriba ya se llama Karara, después Cruzvilque, después Tobraje donde está como bofedalcito, después sigue Quipapampa, quipa quiere decir una planta, después ya se dentra en una parte que se llama Ora, después Valluta, después Chec'acollo, es una piedra poma grande y tiene un hueco y cuando viajan tenían que, con la mano achuntarle en el hueco; ese era un como quien dice si le pasa, le va bien y si no le pasa, ese hueco quiere decir que le va ir mal en el viaje, eso lo tenía antiguamente la gente. Después ya se llama Curiñune, después Callejón, porque es medio cerrado, cerro claro que tiene buen espacio... al llegar al valle Chapisca, Tocontase, entonces la huella llega encima de los cerros, se llama Antechapisca, hasta ahí llega el valle..."
} 
Cuadro No 1

PROCEDENCIA DE LOS PROPIETARIOS Y AREAS

CONTROLADAS

\begin{tabular}{lrrrrr}
\hline Procedencia & Predios & Porcentaje & Superficie & Porcentaje & Propietarios \\
\hline Socoroma & 37 & 45,6 & 139,20 & 41,79 & 17 \\
Putre & 18 & 22,2 & 24,88 & 7,47 & 12 \\
Zapahuira & 8 & 9,8 & 11,42 & 3,42 & 3 \\
Chapiquiña & 5 & 6,2 & 31,16 & 9,35 & 4 \\
Murmuntani & 2 & 2,5 & 3,00 & 0,90 & 2 \\
Villa Industrial & 4 & 4,9 & 14,31 & 4,29 & 2 \\
Perú & 1 & 1,2 & 0,25 & 0,07 & 1 \\
Bolivia & 3 & 3,7 & 16,62 & 4,99 & 2 \\
Sur & 3 & 4,9 & 25,69 & 7,71 & 1 \\
Eriazo & 8 & & 18,15 & 5,44 & \\
Fiscal & 1 & & 11,00 & 3,30 & \\
Sin información & 16 & & 37,35 & 11,21 & \\
& 106 & & 333,03 & 99,94 & 44 \\
\hline
\end{tabular}

Cuadro $\mathrm{N}^{\circ} 2$

\begin{tabular}{|c|c|c|c|c|c|c|c|c|c|c|c|c|c|}
\hline Sectores & 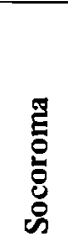 & $\underset{\underline{\Xi}}{2}$ & $\begin{array}{l}\text { 苞 } \\
\text { 总 } \\
\text { N }\end{array}$ & 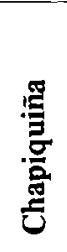 & 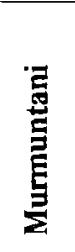 & 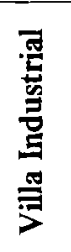 & 忌 & 䄈 & 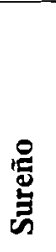 & 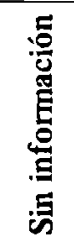 & 胥 & 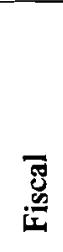 & 哥 \\
\hline Tocontase & 1 & - & - & 2 & & & * & * & & & & & 3 \\
\hline Norte & 4 & 5 & 2 & 1 & & & 1 & & & 2 & & & 15 \\
\hline Chapisca Sur & 2 & 5 & 2 & 2 & & & & 1 & & & 2 & & 14 \\
\hline Chaq & 4 & - & 4 & & & & & & 1 & & 1 & & 10 \\
\hline ala Cala & 2 & 4 & - & & & & & & & 9 & & & 15 \\
\hline Condortave & 6 & 2 & - & & & & & & & & & & 8 \\
\hline ra & 7 & 1 & - & & & & & & & & 1 & & 9 \\
\hline Palma & 1 & 1 & - & & & & & & & 1 & 1 & & 4 \\
\hline avill & 2 & - & ... & & & & & & 1 & & 1 & & 4 \\
\hline hal & 1 & - & - & & & 4 & & & & 3 & 2 & & 10 \\
\hline Tiñare & - & - & - & & & & & & 1 & & & & 1 \\
\hline או & - & - & -- & & & & & & & & & 1 & 1 \\
\hline Millun & 1 & - & - & & & & & & & & & & 1 \\
\hline Arancha & 6 & - & - & & 2 & & & 2 & & 1 & & & 11 \\
\hline TTAL & 3 & 18 & 8 & 5 & 2 & 4 & 1 & 3 & 3 & 16 & 8 & & 106 \\
\hline
\end{tabular}


Los sectores de Tocontase y Chapisca están próximos a la localidad de Molinos (Figura 2), y, por tanto, más alejados del control "desde arriba". Esta situación es especialmente significativa en el caso de los propietarios procedentes de Socoroma; 30 predios $(81.1 \%$ ) se localizan de Chaquire "hacia arriba". La información obtenida en el trabajo de campo en Socoroma corrobora lo anterior, cuando sus habitantes han sostenido que el sector de Molinos "no les pertenecía". Los socoromeños perciben esa localidad como fuera de los límites del área sobre la cual los pueblos de la precordillera tendrían derechos de propiedad y usufructo ${ }^{2}$. Cabe señalar que este control no es sólo "hacia abajo", la mayoría de las familias de Socoroma tienen acceso a tierras situadas en sectores de la precordillera como Putre, Chusmiza, Epispacha, Murmuntani y Zapahuira.

\section{Cuadro $\mathrm{N}^{\circ} 3$}

\section{TAMAÑO DE PREDIOS POR SECTORES}

\begin{tabular}{|c|c|c|c|c|c|c|c|c|c|c|c|c|c|c|c|}
\hline Sectores & 苞 & 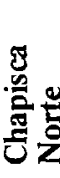 & $\frac{\sqrt{8}}{\frac{\infty}{2}}$ & 帝 & $\begin{array}{l}\frac{\pi}{\pi} \\
\frac{\pi}{\pi} \\
\tilde{J}\end{array}$ & 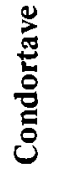 & 站 & 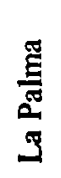 & 莺 & 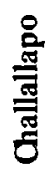 & 苞 & 龒 & 㗐 & 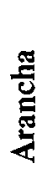 & $\frac{2}{E}$ \\
\hline - 0,50 & & 7 & 4 & 1 & 7 & 1 & & & & 1 & & & & 2 & 23 \\
\hline $0,51 \cdot 1,00$ & & 6 & 2 & 1 & 3 & 1 & 2 & & & 2 & & & & 1 & 18 \\
\hline $1,01-2,00$ & & 2 & 2 & 3 & 4 & 1 & 3 & 1 & 2 & 1 & & & & 1 & 20 \\
\hline $2,01-3,00$ & 1 & & 2 & 3 & 1 & 4 & 2 & & & 2 & & & & 1 & 16 \\
\hline $3,01-4,00$ & & & & 2 & & & 1 & & 1 & 2 & & & & 2 & 8 \\
\hline $4,01-5,00$ & & & 2 & & & & 1 & 1 & & & & & & 2 & 6 \\
\hline $5,01-10,00$ & 1 & & 2 & & & 1 & & 1 & & 2 & & & & 1 & 8 \\
\hline $10,01-15,00$ & 1 & & & & & & & & & & & 1 & 1 & & 3 \\
\hline $15,01-20,00$ & & & & & & & & 1 & & & & & & & 1 \\
\hline $20,01-+$ & & & & & & & & & & & 1 & & & 1 & 2 \\
\hline Sin inform. & & & & & & & & & 1 & & & & & & 1 \\
\hline
\end{tabular}

$\begin{array}{llllllllllllllll}\text { TOTAL } & 3 & 15 & 14 & 10 & 15 & 8 & 9 & 4 & 4 & 10 & 1 & 1 & 1 & 11 & 106\end{array}$

\footnotetext{
${ }^{2}$ La descripción obtenida en Socoroma de la cabecera del valle es la siguiente: ..."se llama Vilacollo, esa es la última; empiezan los terrenos para abajo, después Asirune y una parte que se llama lchasca y otra que se llama Vinto, otra Ancocollo, al frente se llama Guacharaque; después más abajo Millune, más abajo Sausine, más abajo Tinaku, después al frente se llama Challallaku, más abajo Guakullane, al frente Parnan, después llegamos a Sora. Después de Sora se llama Condortave, más abajo Kala Kala, al frente Chaquire, para el lado de abajo Intil, ya llegamos a Chapisca. De Chapisca se llama Tocontase, luego Cantera, al frente Patachiza, ya llegamos a Molinos"'.
} 
En el Cuadro $N^{\circ} 3$ se puede apreciar una notable concentración de predios con una superficie inferior a 3 Há.; sin embargo, dos de los sectores, Chapisca Norte y Cala Cala, tienen un número de predios proporcionalmente alto con un promedio de superficie inferior a 1,0 Há. En el otro extremo, se verifica la existencia de 6 predios con superficies mayores a 10 Há., lo que modifica significativamente el tamaño predial promedio. Este, excluyendo los predios mencionados. es de 2,06 Há.

En el Cuadro $N^{\circ} 4$ se muestra la relación entre la superficie de los predios y procedencia de sus propietarios.

\section{Cuadro $\mathrm{N}^{\circ} 4$}

\section{Pueblos / procedencia}

Há.

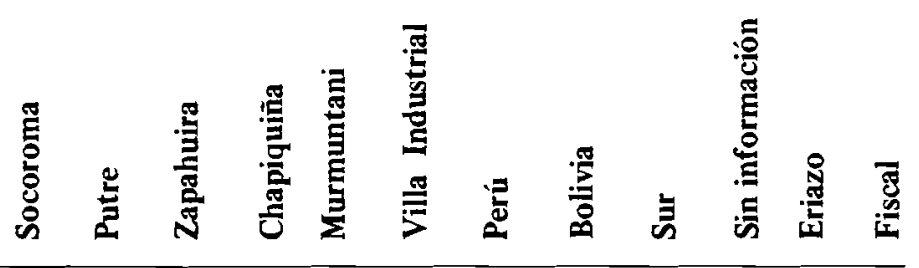

\begin{tabular}{|c|c|c|c|c|c|c|c|c|c|c|c|c|}
\hline - 0,50 & 5 & 5 & 2 & & 1 & & 1 & & & 5 & 2 & \\
\hline $0,51 \cdot 1,00$ & 4 & 6 & 3 & & & 1 & & & & 4 & 1 & \\
\hline $1,01-2,00$ & 9 & 2 & 1 & 2 & & 1 & & & 1 & 3 & 2 & \\
\hline $2,01 \cdot 3,00$ & 9 & 2 & 1 & & 1 & 1 & & 1 & & 1 & & \\
\hline $3,01-4,00$ & 5 & & 1 & & & & & & & 1 & 1 & \\
\hline $4,01-5,00$ & 1 & 2 & & & & & & 1 & & 1 & 1 & \\
\hline $5,01-10,00$ & 2 & 1 & & 2 & & 1 & & 1 & & & 1 & \\
\hline $10,01-15,00$ & 1 & & & 1 & & & & & & & & 1 \\
\hline $15,01-20,00$ & & & & & & & & & & 1 & & \\
\hline $20,01-+$ & 1 & & & & & & & & 1 & & & \\
\hline Sin inform. & & & & & & & & & 1 & & & \\
\hline TOTAL & 37 & 18 & 8 & 5 & 2 & 4 & 1 & 3 & 3 & 16 & 8 & 1 \\
\hline
\end{tabular}

De un total de 37 predios en poder de socoromeños, $18(51,0 \%)$ poseen superficies que van de 1 a 3 Há. Esto contrasta notablemente con la situación que muestran los terrenos controlados por los putreños: el $61,0 \%$ (11) de los predios tienen una superficie inferior a 1 Há. ${ }^{3}$.

${ }^{3}$ Las personas consultadas en Socoroma coincidieron en señalar como territorio de putreños los sectores más cercanos a Molinos; y a partir de Sora aproximadamente pertenecería a Socoroma: "... de Chapisca para arriba, es ya Sora, Chaquire y eso les pertenece a los socoromeños, así decía antiguamente, por eso que hay un templo..." 
Los cuadros entregados hasta el momento permiten mostrar la distribución y concentración de la tierra a nivel de poblados. No obstante nada dicen respecto de la concentración real de la propiedad, es decir, el control diferenciado que ex iste sobre la tierra por parte de los sujetos en un determinado período.

Antes de analizar las características que asume la concentración de la tierra en la cabecera del valle, es necesario referirse a ciertas particularidades del ordenamiento territorial ligado a la producción. Tanto en Socoroma como Lluta, los habitantes efectúan una clasificación espacial del factor tierra, de acuerdo a la aptitud reconocida para desarrollar determinados cultivos, dando origen a un ordenamiento predial en el que las familias controlan tierras en diversos lugares. Por tanto, la noción de concentración de la propiedad que hace referencia a la cantidad de hectáreas bajo la dirección productiva de una persona (natural o jurídica), en este caso, debe ser complementada con la de númere y ubicación de predios en poder de aquélla.

Si se cruza la información del Cuadro $\mathrm{N}^{\circ} 1$ con la del $\mathrm{N}^{\circ} 5$ se comprueba que el número de predios no coincide con el número de propietarios. Al analizar la ocurrencia del fenómeno en cada uno de los poblados que aparecen controlando tierras en el valle, se tiene que 17 personas oriundas de Socoroma son propietarias de 37 predios. En los otros casos la relación es: Zapahuira, 8 predios, 3 propietarios; Chapiquiña, 5 predios, 4 propietarios; Murmuntani, 2 predios, 2 propietarios y Villa Industrial, 4 predios, 2 propietarios.

En el Cuadro $\mathrm{N}^{\circ} 5$ se da cuenta de la estructura de propiedad existente en el valle (se consideran solamente las propiedades de los sujetos nativos de poblados precordilleranos). Algunos de los resultados que se desprenden de su análisis son:

a) El $65,0 \%$ de los propietarios controla un solo predio. El resto se distribuye de la siguiente manera. Un $12,5 \%$ es propietario de dos predios; el $10,0 \%$ controla 3 predios; el $5,0 \%$ controla 4 predios. Los tres propietarios que restan $(7,5 \%)$ controlan 5,6 y 7 predios, respectivamente.

b) El $17,5 \%$ de los casos poseen propiedades cuya superficie total va de 5 a 10 Há.

c) El $52,5 \%$ de los casos tienen propiedades inferiores a 3 Há.

d) Sólo un 5,0\% de los propietarios controlan superficies superiores a las 20 Há.

A continuación, a modo de ejemplo, se ilustra cómo están conformadas algunas propiedades.

El predio que aparece en el Cuadro $\mathrm{N}^{\circ} 4$ en el estrato de 10 a 15 Há. integra, junto a otros seis predios, una sola propiedad. Cinco de los predios que la conforman están localizados en el sector de Sora, ocupando una superficie de 12,10 Há., que representa el 64,9\% de las tierras de aquella localidad. Algo similar acontece con la propiedad 


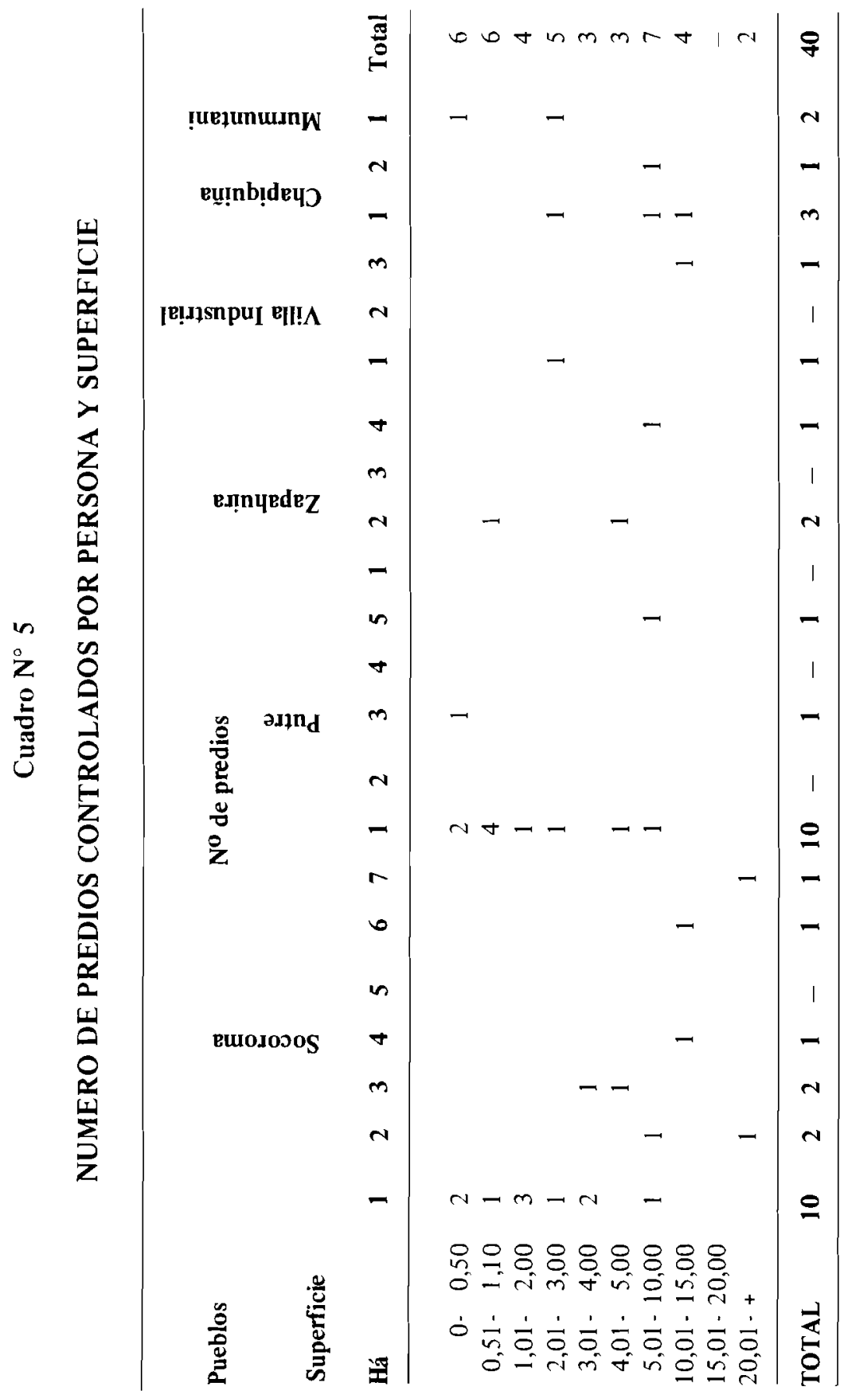


que reúne seis predios; cuatro de ellos están en el sector de Chaquire y ocupan el $45,0 \%$ de la superficie del lugar.

No obstante, sin aparecer registrados 26 propietarios que controlan un solo predio, este número se reduce al incorporar antecedentes de relaciones de parentesco existentes entre algunos propietarios.

A continuación se entregan algunos antecedentes que permiten formarse una idea de la relevancia de estas tierras para la economía de la población local.

E1 interés por los terrenos de Lluta radica en el conocimiento de sus potencialidades productivas a pesar de las limitantes que impone, principalmente, el agua empleada en el riego. Si bien el río Lluta trae agua en abundancia, éstas tienen un alto componente salino a raíz de las aguas que vierte en él el río Azufre, afluente que nace en el Altiplano a los pies del volcán Tacora.

El maíz y la alfalfa, principales cultivos del valle, han demostrado ser resistentes a estas condiciones, a lo que ha contribuido, además, la tecnología desarrollada para purificar el agua. Ambos rubros generan una producción orientada a la reposición (semillas), consumo (humano y animal) y venta.

El uso del maíz difiere según la zona o sector que lo demande. La semilla es comprada por agricultores de los valles de la precordillera y de las partes bajas del valle de Lluta, para evitar regresiones genéticas; del Altiplano la población demanda maíz para hacer "tostado", uno de los componentes centrales de su dieta. Los choclos son comercializados en los mercados de la ciudad de Arica.

La alfalfa, principal forrajera de la zona, es empleada, además, para "mejorar" la calidad de la tierra que ha sido utilizada en el cultivo del maíz por tres años en forma consecutiva. Como en el caso del maíz, la semilla de alfalfa renueva el stock del resto del valle, aunque el medio impone restricciones a su cultivo en determinados sectores. Chapisca es un buen ejemplo de ello. La presencia de neblinas que avanzan por el valle desde la costa, afectan la producción de semilla de alfalfa. Esto resulta particularmente relevante si se considera que la comercialización de esta semilla es uno de los objetivos de su producción.

\section{Consideraciones finales}

La situación descrita para Socoroma podría corresponder a una modalidad de control espacial denominado modelo compacto (según Brush, citado CAmino, 1980), característico de pequeños valles con diferenciación de micro-ambientes a cortas distancias; en este modelo las unidades sociales mantienen un control casi continuo de diversos pisos altitudinales. Socoroma y Putre lograron controlar tierras distantes a 35 kilómetros, aproximadamente, hacia el mar; y en la misma precordillera algunas unidades familiares de Socoroma llegaron a poseer tierras en sectores cuya distancia al poblado fluctuaba entre 5 y 8 
kilómetros. Al respecto, hemos dicho que actualmente la población asentada en la cabecera del valle y en Socoroma reconoce a la localidad de Molinos como el límite de las propiedades de los pueblos de la precordillera. Este modelo de ocupación, con un límite claro en Molinos, situado a $55 \mathrm{kms}$ aproximadamente de la ciudad de Arica, entre los $18^{\circ} 22^{\prime}$ Latitud Sur y $\operatorname{los} 69^{\circ} 54^{\prime}$ Longitud Oeste y a $932 \mathrm{mts}$ sobre el nivel del mar, es similar a la situación existente en la primera mitad del siglo XVIII; en Molinos y áreas aledañas en dirección a la costa existían, al menos 3 haciendas: Hacienda de Molinos, Hacienda Taipimarca y Hacienda Churiña (Hidalgo et al., 1988: 92). Esta misma localidad ha sido descrita, recientemente, como un espacio en que la cultura occidental y la and ina articulan un sistema en precario equilibrio y permanentes tensiones que se expresan en el ámbito de educación, lenguaje, salud, organización familiar, estructura de poder, formas de producción y religión (Galdames, L.A. y W. Ríos, 1985: pp. 203-296).

El desplazamiento hacia zonas bajas (cabecera del valle) es análoga a la situación de la cabecera del rio Azapa (PlatT, 1977).

El sistema de control territorial se manifiesta en el comportamiento económico de las unidades familiares, en un contex to donde se encuentran presente otras dimensiones de la vida social. Las personas pueden acceder a tierras fuera de la comunidad mediante la herencia, compra o mediería, y perder los derechos adquiridos al dejar de cultivar las tierras. Como se señalara anteriormente, la inscripción legal de predios ha significado para unos transformarse en propietarios; para otros ser despojados de la tierra, en muchos casos manifestando una aceptación que denota cierta resignación.

Al constatar que en la mayoría de los trabajos antropológicos que describen los sistentas de verticalidad o complementariedad la unidad de estudio es el pueblo o comunidad, sostenemos que es posible alcanzar niveles de análisis más rigurosos para tratar el control de la tierra, si las unidades seleccionadas son las familias. Cada asentamiento poblado pertenece a una estructura espacial mayor, donde la densidad de las relaciones disminuye hacia la periferia. Un ejemplo de lo anterior lo encontramos en el sistema de "cargos" de la iglesia de Socoroma. Desde los caserios precordilleranos más cercanos como Murmuntani y Zapahuira, acudían temporalmente familias a "cumplir" "cargos" en la iglesia del pueblo.

Este hecho que podría interpretarse como una relación de subordinación, da paso a una explicación más compleja si se considera que el sistema de cumplimiento de cargos constituyó un requisito para poder tener derecho a agua para riego. Frente a esto se pueden concluir al menos dos cuestiones: 1) el sistema de cargos neutralizaba el conflicto entre personas de diferentes asentamientos que acceden a tierras en una misma área; y 2 ) es un mecanismo empleado por personas $y / o$ familias que habiendo accedido a tierras mediante compra o herencia, deben obtener el reconocimiento de la comunidad 
como un integrante más de ella, lo que otorga, entre otros derechos, agua.

Se recuerda que hasta Socoroma llegaban personas de Pachama para participar en las actividades religiosas. Cómo explicar este hecho, si no es a través del estudio de la organización de la produccióis al interior de los niveles domésticos, que han mantenido vínculos económicos entre ambos asentamientos.

En el área andina persisten relaciones tradicionales, principalmente en el nivel organizacional; estos grupos han sido capaces de integrar y combinar elementos externos a su herencia cultural (Durston, 1983). La complementariedad de recursos entre precordillera y cabecera del valle, no es sino la expresión de una de las relaciones entre zonas ecológicas diferentes propia de la forma de producción andina.

La percepción de diversos microclimas o aptitudes de la tierra ha estado en la base de la organización socioeconómica. La utilización de la tierra en la producción ha sido de una flexibilidad tal que ha permitido -y de ello da cuenta la historia-, la articulación de formas de producción locales al modo de producción dominante. La introducción de ovinos y vacunos, de animales de carga (asnales y mulares), cultivos de alfalfa y, últimamente, de orégano, ilustran los cambios experimentados en la producción como respuesta a los requerimientos, directos o indirectos, del mercado de bienes.

La situación en la actualidad muestra cambios en dos direcciones; 1) con respecto a la población que trabaja las tierras y 2) con respecto al destino de la producción. Existe un cierto consenso en que las personas que estarían cultivando las tierras de la cabecera del valle de Lluta son descendientes o parientes de personas que tienen y trabajan tierras en Socoroma; aquellas, además, habrian fijado su residencia en la ciudad de Arica. También hay consenso respecto a un tiempo pasado en que los socoromeños "iban a cultivar a Lluta"; la mayoría de los habitantes del pueblo tiene antecedentes o recuerda los viajes que se efectuaban al valle desde Socoroma. No obstante, podríamos postular que el reconocimiento del control sobre la tierra estaba dado por el uso relativamente continuo. Al ser abandonadas, como ellos mismos reconocen, son trabajadas por otras personas que las arriendan o simplemente las usan cuando su dueño no se apersona. En este último caso, encontramos en sus respuestas una cierta aceptación del hecho de perderlas: "los que viven se harán dueños", "se han de hacer dueños".

El otro cambio que señalamos más arriba se refiere a la presencia del mercado; la especialización de la producción en el área andina formaba parte de un sistema en el que el intercambio era el mecanismo utilizado para que la población, localizada en diferentes altitudes accediera a una alimentación básica equilibrada. Hoy, la especialidad persiste, pero se ha verificado un cambio en el destino de la producción. El mercado nacional y extranjero demanda bienes que produce el área andina; esta nueva forma de especialización representa una nueva constricción a las relaciones de complementariedad; cada piso 
ecológico del interior de Arica se está articulando directamente con el mercado de esta ciudad.

Hasta hoy, la flexibilidad para adaptarse a imposiciones y restricciones macrosociales, refleja el proceso dialéctico por el cual se explica la persistencia de este campesinado con rasgos que lo identifican como integrante de una cultura andina.

\section{BíBLIOGRAFÍA}

Camino, Alejandro. "Tiempo y espacio en la estrategia de subsistencia andina: Un caso en las Vertientes Orientales Sudperuanas", Senri Ethonological Studies, El hombre y su ambiente en los Andes Centrales [Osaka], No 10, 1980, pp. $11-35$

Castro, Milka. "Estrategias socioculturales de subsistencia en las comunidades aymaras altoandinas en el interior de la Provincia de Arica". El hombre y los ecosistemas de montaña, UNESCO. Uruguay, vol. II, 1982, pp. 99-132.

Castro, Milka y Bahamondes, Miguel. "Cambios en la tenencia de la tierra en un pueblo de la precordillera del norte de Chile: Socoroma", Revista Chilena de Antropologia [Santiago], No 6, 1987, pp. 35-57.

Durston, John. "Comunidad andina, gestión de recursos y diferenciación social", en sobrevivencia campesina en ecosistemas de altura, CEPAL-PNUMA. Santiago, vol. I, 1983, pp. 91-137.

Hidalgo, J. et al.: "Padrón de la doctrina de Belén en 1813: un caso de complementariedad tardía", en Documento de Trabajo No 4. Universidad de Tarapacá, 1988.

Galdames, L.A. y Ríos W.: "Percepción del conflicto integración vs. desintegración de los valles costeños de Arica: Testimonio vivo de un 'Big Man' en la Comunidad de Molinos". Actas del Primer Congreso Chileno de Antropología, Santiago, 1985, pp. 201-208.

Platt, Tristán. "Experiencia y experimentación: Los asentamientos andinos en las cabeceras del valle de Azapa", Chungará [Arica], No 5, 1975, pp. 33-60. 